\title{
Mitochondrial energy utilization maintains young status in the trophocytes and oenocytes of old queen honeybees
}

\author{
Chin-Yuan $\mathrm{Hsu}^{1,2}$, Cheng-Yen Lu \\ ${ }^{1}$ Department of Biomedical Sciences, College of Medicine, Chang Gung University, 259, Wen-Hwa 1st Road \\ Kwei-Shan, 333, Tao-Yuan, Taiwan \\ ${ }^{2}$ Graduate Institute of Biomedical Sciences, College of Medicine, Chang Gung University, Tao-Yuan, Taiwan
}

Received 21 July 2014 - Revised 5 December 2014 - Accepted 9 January 2015

\begin{abstract}
The lifespans of queen honeybees (Apis mellifera) are much longer than those of worker bees. Mitochondrial energy utilization in the trophocytes and oenocytes of worker bees during aging has been determined, but it remains unknown in queen bees. In this study, mitochondrial energy utilization was assayed in the trophocytes and oenocytes of young and old queen bees. The mitochondrial density and mitochondrial membrane potential $(\Delta \psi \mathrm{m})$; nicotinamide adenine dinucleotide $\left(\mathrm{NAD}^{+}\right)$, nicotinamide adenine dinucleotide reduced form (NADH), and adenosine triphosphate (ATP) levels; $\mathrm{NAD}^{+} / \mathrm{NADH}$ ratio; and relative expression of NADH dehydrogenase 1 (ND1) and ATP synthase normalized against mitochondrial density were not significantly different between young and old queen bees. These results indicate that mitochondrial energy utilization maintains a young status in the trophocytes and oenocytes of old queen bees and that trophocytes and oenocytes have longevity-promoting mechanisms that can be investigated to clarify the secret of longevity in queen bees.
\end{abstract}

aging / mitochondria / energy utilization / honeybee

\section{Scientific abbreviations}

$\Delta \psi \mathrm{m} \quad$ Mitochondrial membrane potential

$\mathrm{NAD}^{+}$Nicotinamide adenine dinucleotide oxidized form

NADH Nicotinamide adenine dinucleotide reduced form

ATP Adenosine triphosphate

ND1 NADH dehydrogenase 1

\section{INTRODUCTION}

Understanding the mechanisms of aging and longevity could improve the health and extend the lifespan of many organisms, including humans. Honeybees (Apis mellifera) provide a unique model for studying aging and longevity because, although worker bees and queen bees develop from the same genome, queen bees have much

Corresponding author: C. Hsu, hsu@mail.cgu.edu.tw Manuscript editor: Klaus Hartfelder longer lifespans. The lifespans of worker bees are 15-38 days in the summer and 150-200 days in the winter, while queen bees live 1-2 years with a maximum of up to 8 years (Page and Peng 2001; Omholt and Amdam 2004; Rueppell et al. 2007; Remolina and Hughes 2008).

Large and irregularly shaped trophocytes attach to small and spherical oenocytes to form a single layer of cells around each segment of honeybee abdomen (Kuterbach and Walcott 1986; Martins et al. 2011). Lack of cell division during adulthood, ease of isolation from the abdomen, and convenient manipulation make trophocytes and oenocytes suitable for use in studies of cellular senescence and longevity (Hsieh and Hsu 2011a, b; Hsu and Chan 2013; Chan et al. 2011; Chuang and Hsu 2013; Hsu and Chuang 2014; Hsieh and Hsu 2013; Hsu and Hsieh 2014; Hsu and $\mathrm{Hu}$ 2014).

Studies of age-related molecules have shown that the trophocytes and oenocytes of old queen bees exhibit higher levels of senescence- 
associated beta-galactosidase, more lipofuscin granules, and higher lipid peroxidation and protein oxidation than those of young queen bees (Hsieh and Hsu 2011b). These results are similar to those reported in worker bees (Hsieh and Hsu 2011a). However, queen bees have much longer lifespans than worker bees, suggesting that the trophocytes and oenocytes of queen bees have longevity-promoting mechanisms.

Studies of oxidative stress and antioxidant enzyme activity have shown that the trophocytes and oenocytes of old queen bees have higher levels of reactive oxygen species (ROS) and higher activity of superoxide dismutase, catalase, and glutathione peroxidase than those of young queen bees (Hsieh and Hsu 2013). These studies suggest that increased oxidative stress and consequent stress defense mechanisms are associated with the longevity of queen bees. In contrast, in worker bees, oxidative stress decreases in trophocytes and oenocytes with age (Hsu and Hsieh 2014).

The trophocytes and oenocytes of old queen bees have similar levels of AMPK activity; FoxO expression; adenosine triphosphate (ATP), ADP, AMP, and cAMP concentrations; SirT1 expression and activity; and PPAR- $\alpha$ expression as those of young queen bees (Hsu and $\mathrm{Hu}$ 2014). These results suggest that energy metabolism in trophocytes and oenocytes is similar between young and old queen bees and is different from that reported in worker bees (Hsu and Chuang 2014). These results are consistent with previous studies showing that FoxO overexpression extends the lifespan of Drosophila (Giannakou et al. 2004, Hwangbo et al. 2004). These results also suggest that the trophocytes and oenocytes of queen bees have longevity-promoting mechanisms because queen bees have longer lifespans than worker bees and old queen bees have FoxO expression similar to young queen bees.

Old queen bees have high accumulations of age-related molecules and high oxidative stress (Hsieh and Hsu 2011b; Hsieh and Hsu 2013). However, energy-regulated molecule expression is similar between young and old queen bees. To clarify these phenomena, we studied mitochondrial energy utilization in the trophocytes and oenocytes of young and old queen bees. In the present study, mitochondrial density, $\Delta \psi \mathrm{m}$, nicotinamide adenine dinucleotide $\left(\mathrm{NAD}^{+}\right)$concentration, nicotinamide adenine dinucleotide reduced form (NADH) concentration, ATP concentration, $\mathrm{NAD}^{+} / \mathrm{NADH}$ ratio, and NADH dehydrogenase 1 (ND1) and ATP synthase expression were evaluated in the trophocytes and oenocytes of young and old queen bees to understand mitochondrial energy utilization in queen bees.

\section{MATERIALS AND METHODS}

\subsection{Queen honeybees}

Queen bees were purchased from a single commercial breeder (Hsinchu, Taiwan). As described in our previous studies (Hsieh and Hsu 2011b; Hsieh and Hsu 2013; Hsu and Hu 2014), young (2-month-old) and old (16-month-old) queen bees were collected from different hives on the same dates for use in the following experiments. The young and old queen bees were mated with drones and were able to lay eggs. Individual queens of each group were dissected with scissors, and their abdominal trophocytes and oenocytes were detached from the cuticle using a knife in honeybee saline (Hsu et al. 2007). Trophocytes and oenocytes were used for the following experiments.

\subsection{Assay of mitochondrial density}

The mitochondrial density was measured as previously described using transmission electron microscopy (TEM) (Hsu and Chan 2011; Chuang and Hsu 2013). Eight microscopy images of the trophocytes near the nucleus from each young and each old queen were analyzed using Photoshop (CS6). This experiment was performed with five biological replicates using a total of five young and five old queen bees.

\subsection{Assay of $\Delta \Psi \mathrm{m}$}

$\Delta \Psi \mathrm{m}$ assays in the trophocytes and oenocytes were performed as previously described using the specific dye tetramethylrhodamine methyl ester (TMRM) (T668; Life Technologies, Grand Island, NY, USA) (Ward et al. 2000; Chuang and Hsu 2013). Briefly, trophocytes and oenocytes were stained with TMRM, washed with PBS, and visualized under a confocal 
microscope (Leica TCS SP2; Leica, Wetzlar, Germany). $\Delta \Psi \mathrm{m}$ was expressed as the red fluorescence intensity/ cell area ratio. Five confocal microscopy images of the trophocytes and oenocytes from each young and each old queen were analyzed using QWin image processing and analysis software (version 2.5, Leica, Wetzlar, Germany) and Photoshop (CS6). This experiment was performed with five biological replicates using a total of five young and five old queen bees.

\subsection{Assay of $\mathrm{NAD}^{+}$and NADH concentration}

$\mathrm{NAD}^{+}$and $\mathrm{NADH}$ were measured in the trophocytes and oenocytes as previously described using an $\mathrm{NAD}^{+}$/ NADH Quantification Kit (K337-100; BioVision, Mountain View, CA, USA) (Chuang and Hsu 2013). Briefly, the trophocytes and oenocytes from one young or old queen bee were extracted with NADH/NAD extraction buffer; the extracted samples were heated for NADH measurement. After background luminescence was recorded, the extracted samples and the extracted and heated samples were measured. The resultant luminescence was normalized to background. Dilutions of an NADH standard solution (0, 20, 40, 60, 80, and $10 \mathrm{pmol} \mu \mathrm{L}^{-1}$ ) were processed concurrently to generate a standard curve, which was used to obtain $\mathrm{NAD}^{+}$and NADH values. Protein concentration was determined using a commercial protein assay reagent (500-0006; Bio-Rad Laboratories, Hercules, CA, USA). The $\mathrm{NAD}^{+}$and NADH concentrations are expressed as micromoles per milligram protein and were used to determine the $\mathrm{NAD}^{+} / \mathrm{NADH}$ ratio. This experiment was performed with five biological replicates using a total of five young and five old queen bees.

\subsection{Assay of ATP concentration}

The ATP concentration in the trophocytes and oenocytes was determined as previously described using an ATP Determination Kit (A22066; Invitrogen, Carlsbad, CA, USA) (Chuang and Hsu 2013). Briefly, the trophocytes and oenocytes from one young or old queen bee were homogenized in phosphate buffer containing protease inhibitors and centrifuged to obtain the resulting supernatant. Protein concentration was determined using a commercial protein assay reagent (5000006; Bio-Rad Laboratories). After recording background luminescence, diluted ATP standard solution $(1,10,100,1000$, and $5000 \mathrm{nM})$ or supernatant was added to the standard reaction solution to measure values. The ATP concentration is expressed as picomoles per milligram protein. This experiment was performed with five biological replicates using a total of five young and five old queen bees.

\subsection{Western blotting}

The trophocytes and oenocytes from one young or old queen bee were homogenized with a blue pestle and sonicator in $100 \mu \mathrm{L}$ of radioimmunoprecipitation buffer containing protease inhibitors (11697498001; Roche Applied Science, Indianapolis, IN, USA), and then centrifuged at $5000 \mathrm{~g}$ for $10 \mathrm{~min}$ at $4{ }^{\circ} \mathrm{C}$ to obtain the supernatant. Protein concentration was determined using a commercial protein assay reagent (500-0006; Bio-Rad Laboratories). Western blotting was performed as previously described (Hsu et al. 2014; Hsu and Chuang 2014; Hsu and Hu 2014) using primary antibodies against ATP synthase (1:1000; produced in-house), ND1 (h00004535-A01, 1:1000; Abnova, Neihu, Taipei, Taiwan), and tubulin (ab6046, 1:10,000; Abcam, Cambridge, MA, USA) and using the horseradish peroxidaseconjugated secondary antibody $(1: 10,000)$. This experiment was performed with five biological replicates using a total of five young and five old queen bees.

\subsection{Statistical analysis}

The differences in the mean values between the two age groups were examined using a twosample $t$ test. $P<0.05$ was considered statistically significant.

\section{RESULTS}

\subsection{Mitochondrial density}

To examine mitochondrial energy utilization in queen bees, we assayed the mitochondrial density in the trophocytes of young and old queen bees. The mitochondrial size in these trophocytes, determined using TEM, was small in young queen 
bees and large in old queen bees (Figure 1a). The mitochondrial area in these trophocytes was significantly lower in young queen bees than in old queen bees $(n=137, P<0.01$; Figure $1 b)$. However, the mitochondrial density, presented as the mitochondrial area/cell area, was not significantly different between young and old queen bees $(n=40, P>0.05$; Figure 1c).

\section{2. $\Delta \Psi \mathrm{m}$}

To further evaluate mitochondrial energy utilization in queen bees, we assayed $\Delta \psi \mathrm{m}$ in the trophocytes and oenocytes of young and old queen bees. The trophocytes and oenocytes were stained with TMRM and showed red fluorescence (Figure 2a). The $\Delta \psi \mathrm{m}$ was presented as the ratio

a

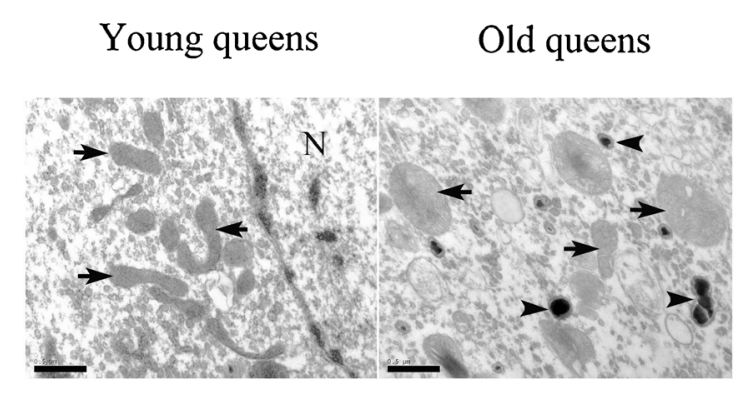

c

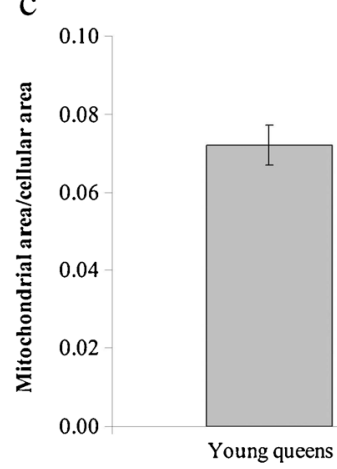

of red fluorescence/cell area, and it was not significantly different between young and old queen bees ( $n=25, P>0.05$; Figure $2 \mathrm{~b})$.

\section{3. $\mathrm{NAD}^{+}, \mathrm{NADH}$, and ATP concentration}

To examine the relationship between $\Delta \psi \mathrm{m}$ and levels of NAD ${ }^{+}, \mathrm{NADH}$, and ATP, we assayed the concentrations of $\mathrm{NAD}^{+}, \mathrm{NADH}$, and ATP in the trophocytes and oenocytes of young and old queen bees. The mean values for $\mathrm{NAD}^{+}$concentration in the trophocytes and oenocytes were 1.05 \pm 0.19 and $1.28 \pm 0.12 \mu \mathrm{mol} \mathrm{mg}{ }^{-1}$ of protein in young and old queen bees, respectively $(n=5$, $P>0.05$; Figure $3 \mathrm{a}$ ). The mean values for $\mathrm{NADH}$ concentration in trophocytes and oenocytes were

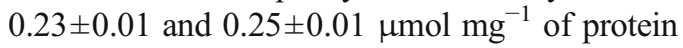

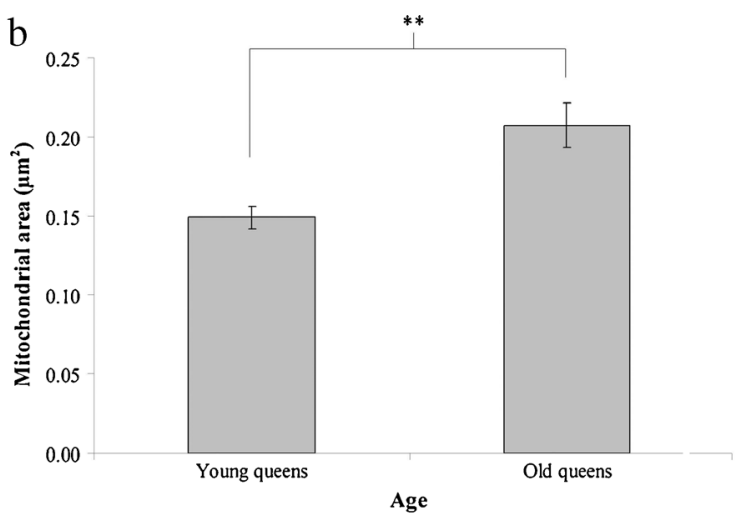

Figure 1. Mitochondrial density in the trophocytes of queen bees. a Mitochondria in trophocytes were examined using TEM. Scale bar, $1 \mu \mathrm{m}$. Arrows point to mitochondria. Arrowheads point to iron granules. b Mitochondrial area, presented as the mean \pm standard error of the mean $(S E M)$, was calculated from the TEM images. c Mitochondrial density is presented as the mitochondrial area/cellular area ratio. Bars are presented as the mean \pm SEM. Asterisks indicate statistically significant difference $(* * P<0.01$; two-sample $t$ test). 
a

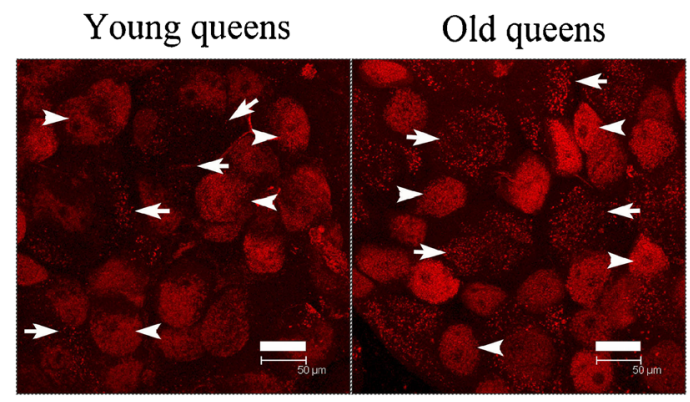

b 150

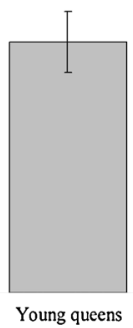

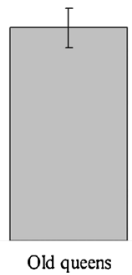

Age

Figure 2. $\Delta \Psi \mathrm{m}$ in the trophocytes and oenocytes of queen bees. a Representative confocal images of the stained TMRM. Scale bar, $50 \mu \mathrm{m}$. Arrows point to trophocytes. Arrowheads point to oenocytes. b $\Delta \psi \mathrm{m}$ is presented as the red fluorescence/cellular area ratio. The red fluorescence/cellular area ratio was normalized to that in young worker bees. The results are presented as the mean \pm SEM and are expressed as percentages.

in young and old queen bees, respectively $(n=5$, $P>0.05$; Figure $3 \mathrm{~b})$. The mean values for $\mathrm{NAD}^{+} /$ $\mathrm{NADH}$ ratio in trophocytes and oenocytes were

a

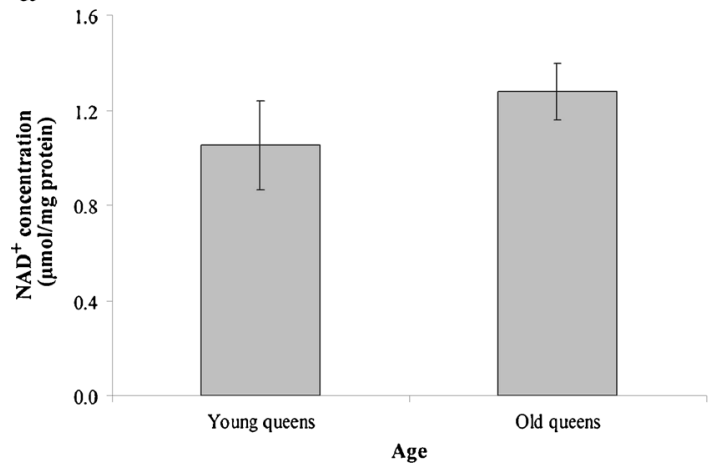

c

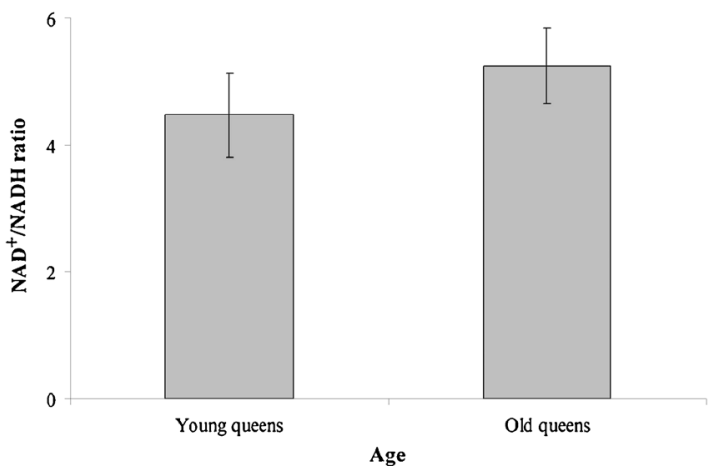

$4.47 \pm 0.67$ and $5.25 \pm 0.59$ in young and old queen bees, respectively ( $n=5, P>0.05$; Figure $3 \mathrm{c}$ ). The mean values for ATP concentration in trophocytes
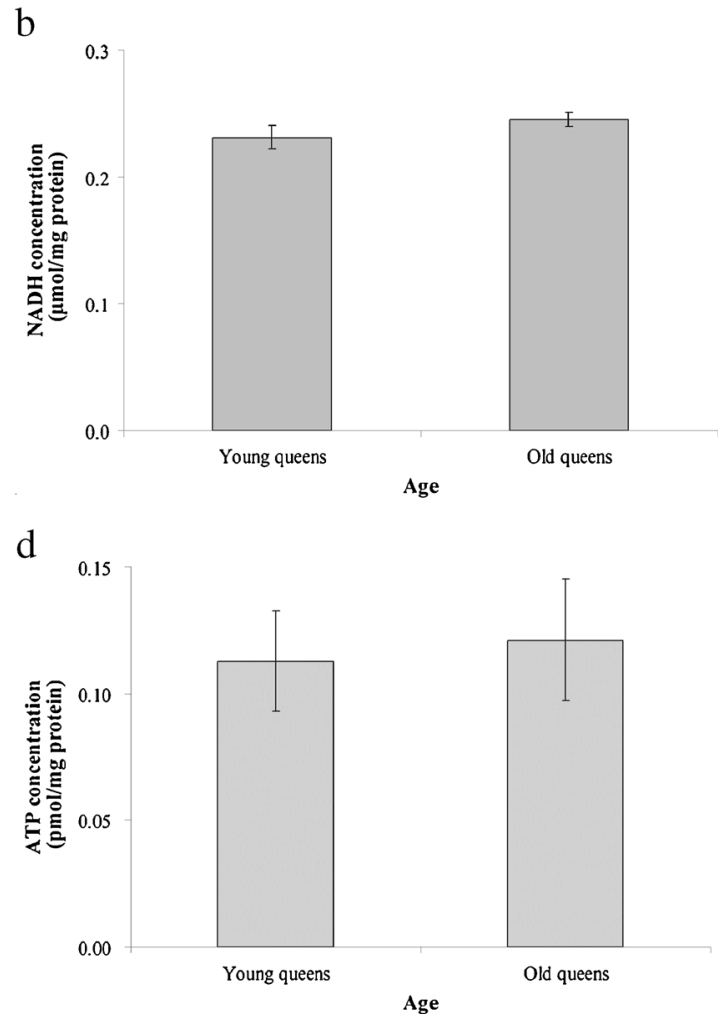

Figure 3. $\mathrm{NAD}^{+}$concentration (a), NADH concentration (b), $\mathrm{NAD}^{+} / \mathrm{NADH}$ ratio $(\mathbf{c})$, and $\mathrm{ATP}$ concentration $(\mathbf{d})$ in the trophocytes and oenocytes of queen bees. The values denote the mean \pm SEM. 
and oenocytes were $0.11 \pm 0.02$ and $0.12 \pm$ $0.02 \mathrm{pmol} \mathrm{mg}^{-1}$ of protein in young and old queen bees, respectively ( $n=5, P>0.05$; Figure $3 \mathrm{~d})$.

\subsection{ND1 and ATP synthase expression}

To extend our evaluation of $\mathrm{NAD}^{+}$and ATP, we assayed the expression of ND1 and ATP synthase in the trophocytes and oenocytes of young and old queen bees. ND1 expression was lower in young queen bees than in old queen bees (Figure $4 \mathrm{a}$ ), and this difference was statistically significant ( $n=5, P<0.05$; Figure $4 \mathrm{~b}$ ). Similarly, expression of ATP synthase was also low in young queen bees and high in old queen bees

a
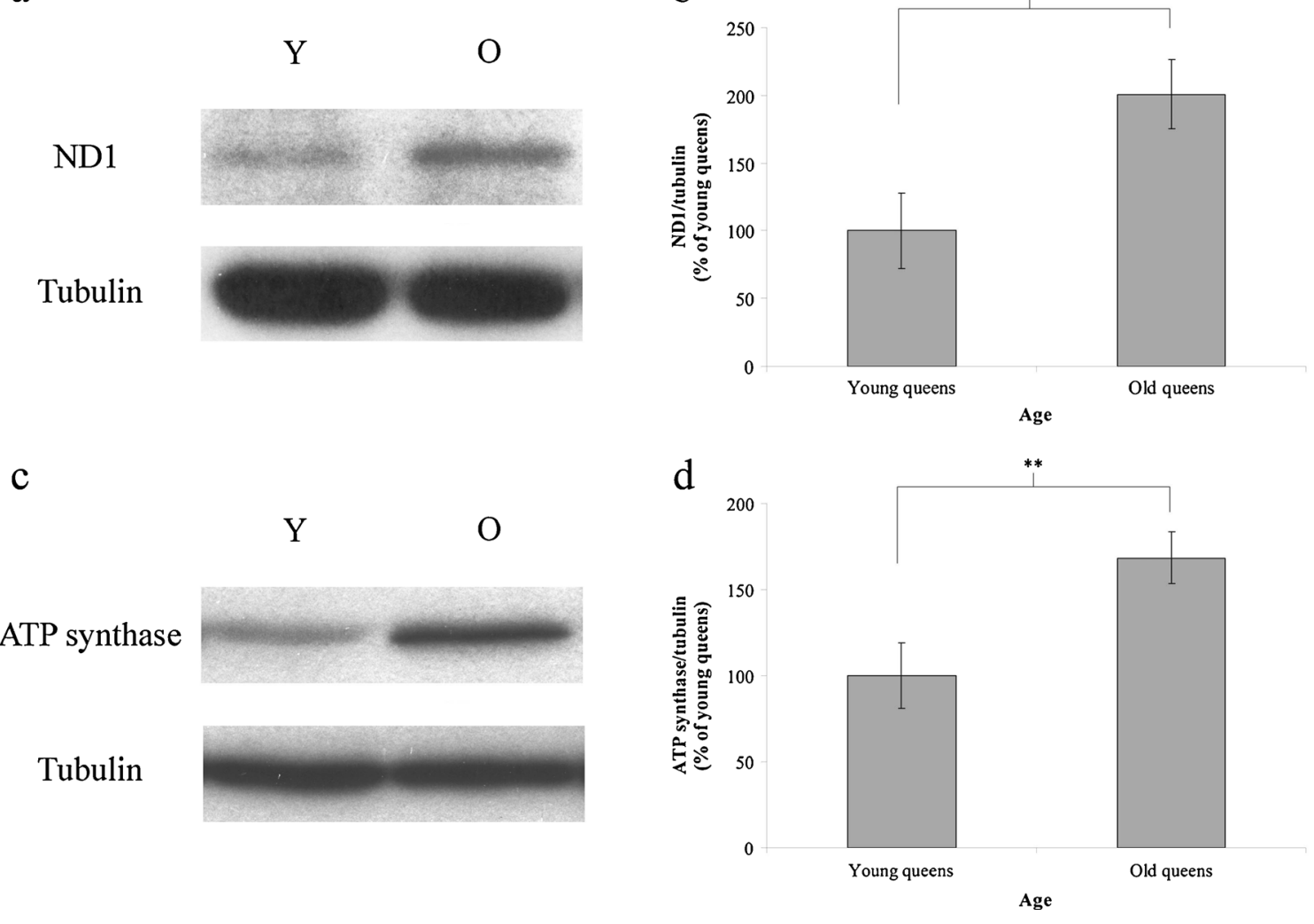

Figure 4. ND1 and ATP synthase expression in the trophocytes and oenocytes of queen bees. a ND1 protein concentration was analyzed using Western blotting. Tubulin served as a loading control. b ND1 expression was normalized to that in young worker bees. The results are presented as the mean \pm SEM and are expressed as percentages. c ATP synthase concentration was analyzed through Western blotting. Tubulin served as a loading control. d ATP synthase expression was normalized to that in young worker bees. The results are presented as the mean \pm SEM and are expressed as percentages. Asterisks indicate a statistically significant difference $\left({ }^{*} P<0.05\right.$, ${ }^{*} P<0.01$; two-sample $t$ test). $Y$ young queen bees, $O$ old queen bees.
(Figure 4c), and this difference was statistically significant $(n=5, P<0.05$; Figure $4 \mathrm{~d})$. Because ND1 and ATP synthase are located in the mitochondria, the expression levels of these enzymes were normalized to the mitochondrial area. The normalized ND1 and ATP synthase levels were not significantly different between young and old queen bees $(n=5, P>0.05$; Figure $5 \mathrm{a} ; n=5$, $P>0.05$; Figure 5b).

\section{DISCUSSION}

In the present study, we evaluated mitochondrial energy utilization in the trophocytes and oenocytes of young and old queen bees.

b 
a

150

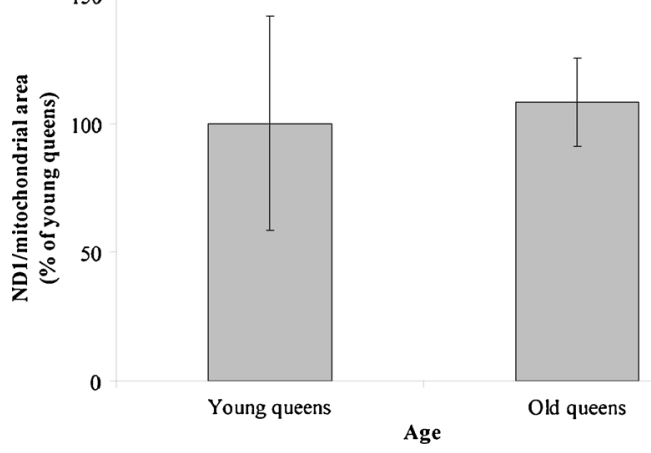

b

150

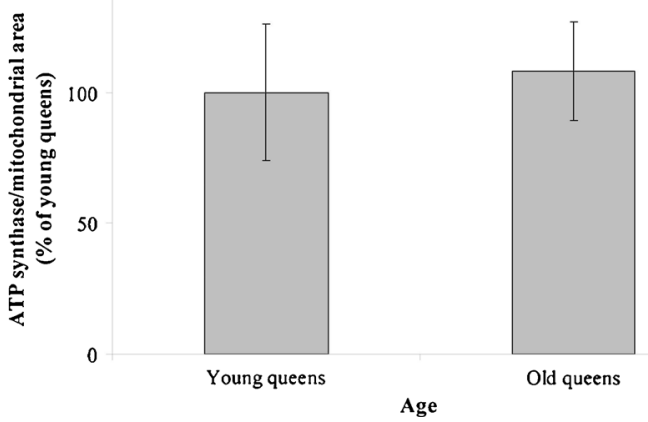

Figure 5. ND1 and ATP synthase expression normalized to mitochondrial density. a ND1/mitochondrial density ratio. b ATP synthase/mitochondrial density ratio. Ratios are expressed relative to those in young worker bees. The results are presented as the mean \pm SEM and are expressed as percentages.

Young and old queen bees had similar mitochondrial density; $\Delta \psi \mathrm{m} ; \mathrm{NAD}^{+}, \mathrm{NADH}$, and ATP concentrations; and area-normalized ND1 and ATP synthase levels. These results suggest that mitochondrial energy utilization is unchanged in the trophocytes and oenocytes of young and old queen bees, and these cells seem to have longevity-promoting mechanisms that can be used to investigate the longevity of queen bees.

\subsection{Mitochondrial density}

An increase in mitochondrial density with age has been reported in many contexts, such as in senescent human diploid fibroblasts (Martinez et al. 1991; Xu and Finkel 2002); the lung and brain of aging humans (Lee et al. 1998; Barrientos et al. 1997; Lee et al. 2000); the liver, heart, and brain of old rats (Gadaleta et al. 1992); the liver of old mice, rats, guinea pigs, rabbits, sheep, cows, hamsters, and humans (Passos et al. 2007); and shorter-lived mammals (Passos et al. 2007). Similarly, the mitochondrial density increases with age in the trophocytes and oenocytes of 50-dayold worker bees (Chuang and Hsu 2013). In the present study, however, the mitochondrial density in the trophocytes and oenocytes of young and old queen bees was similar, although the old queen bees were 16 months old. These results most likely reflect delayed senescence mechanisms in the trophocytes and oenocytes of queen bees, which maintain these cells in a young status.

Although mitochondrial density did not appear to change, a change in mitochondrial morphology was observed. The mitochondrial area (and thus presumably the mitochondrial volume) of old queen bees was larger than that of young queen bees, and the mitochondrial morphology of old queen bees was more ovoid than that of young queen bees. In addition, because mitochondrial density did not appear to change, we infer that the size of the trophocytes of old queen bees was also increased. The enlargement of the mitochondria and trophocytes in old queen bees may be associated with cellular functions in old queen bees. Further research is required to clarify this point.

\section{2. $\Delta \Psi \mathrm{m}$}

$\Delta \Psi \mathrm{m}$ controls respiration, ATP synthesis, and ROS production. In turn, $\Delta \Psi \mathrm{m}$ is controlled through electron transport and proton leakage (Nicholls 2004). $\Delta \Psi \mathrm{m}$ decreases with age in the hepatocytes of rats and mice (Hagen et al. 1997; Kokoszka et al. 2001), the lymphocytes of mice (Wikowski and Micklem 1985; Rottenberg and $\mathrm{Wu}$ 1997), and the heart of rats (Savitha and Panneerselvam 2006). Similarly, $\Delta \Psi \mathrm{m}$ decreases with age in the trophocytes and oenocytes of worker bees (Chuang and Hsu 2013). These 
phenomena reflect mitochondrial dysfunction during the aging process (Ames et al. 1995; Trifunovic and Larsson 2008; Artal-Sanz and Tavernarakis 2008; López-Lluch et al. 2008; Chanséaume and Morio 2009). In this study, however, the $\Delta \Psi \mathrm{m}$ in the trophocytes and oenocytes of young queen bees was similar to that in old queen bees, potentially reflecting delayed senescence mechanisms in these cells that maintain them in a young status.

\section{3. $\mathrm{NAD}^{+}, \mathrm{NADH}$, and ATP concentrations}

Protons from NADH are pumped out of the mitochondrial matrix, creating a proton gradient that forms the $\Delta \Psi \mathrm{m}$. A decline in this activity results in a decrease in $\Delta \Psi \mathrm{m}$ and a subsequent decrease in $\mathrm{NAD}^{+}$concentration. $\mathrm{NAD}^{+}$concentration decreases with age in the pancreatic $\beta$ cells and neurons of mice (Ramsey et al. 2008; Imai 2009) and in the liver, heart, kidney, and lung of rats (Braidy et al. 2011). Similarly, the $\mathrm{NAD}^{+}$ concentration and $\mathrm{NAD}^{+} / \mathrm{NADH}$ ratio decreases with age in the trophocytes and oenocytes of worker bees (Chuang and Hsu 2013). In this study, however, the $\mathrm{NAD}^{+}$concentration and $\mathrm{NAD}^{+} / \mathrm{NADH}$ ratio in trophocytes and oenocytes were similar in young and old queen bees.

ATP concentration decreases with age in the gastric mucosa and muscle of humans (Kawano et al. 1991; Gurd et al. 2008), the blood and brain of mice (Jayachandran et al. 2005; Joo et al. 1999), the erythrocytes of rabbits (Subasinghe and Spence 2008) and cows (Bartosz et al. 1982), and the heart of rats (Guerrieri et al. 1996). Similarly, we have found that ATP concentration decreases with age in the trophocytes and oenocytes of worker bees (Hsu and Chan 2013; Chuang and Hsu 2013). In this study, however, the ATP concentration in trophocytes and oenocytes was similar in young and old queen bees. This finding is consistent with the results obtained for $\triangle \Psi \mathrm{m}, \mathrm{NAD}^{+}$concentration, and $\mathrm{NAD}^{+} / \mathrm{NADH}$ ratio. A possible explanation for these results is that the trophocytes and oenocytes of queen bees have delayed senescence mechanisms that maintain these cells in a young status.

\subsection{ND1 and ATP synthase expression}

ND1 expression increased with age in the trophocytes and oenocytes of queen bees. This finding is consistent with the previous finding that NADH dehydrogenase expression increases with age in the muscle of rats (Chang et al. 2007), the lung fibroblasts of humans (Allen et al. 1999), and the trophocytes and oenocytes of worker bees (Chuang and Hsu 2013). The expression of ATP synthase also increased with age in the trophocytes and oenocytes of queen bees. Previous studies have reported similar findings, showing that the expression of ATP synthase increases with age in the brain and muscle of rats (Nicoletti et al. 1995; Chang et al. 2007; Doran et al. 2008; Donoghue et al. 2010), the muscle of humans (Gelfi et al. 2006), and the trophocytes and oenocytes of worker bees (Chuang and Hsu 2013).

Although ND1 and ATP synthase expression, measured in absolute terms, both increased with age in the trophocytes and oenocytes of queen bees, the levels of ND1 and ATP synthase normalized against the mitochondrial density were not significantly different between young and old queens. This observation is consistent with the results of a previous study of worker bees (Chuang and Hsu 2013). In worker bees, ND1 and ATP synthase levels normalized against the mitochondrial density were not significantly different between young and old worker bees, but $\mathrm{NAD}^{+}$and ATP concentrations decreased in old worker bees. These phenomena suggest that old worker bees have reduced the efficiency of ND1 and ATP synthase (Chuang and Hsu 2013). NAD ${ }^{+}$ and ATP concentrations were also not significantly different between young and old queen bees, indicating ND1 and ATP synthase do not experience age-related declines in efficiency.

Taken together, the results of the present study indicate that young and old queen bees had similar mitochondrial density; $\Delta \psi \mathrm{m} ; \mathrm{NAD}^{+}, \mathrm{NADH}$, and ATP concentration; and ND1 and ATP synthase expression. These findings suggest that mitochondrial energy utilization does not decline in the trophocytes and oenocytes of old queen bees. These results are consistent with a recent study showing that energy-regulated molecules 
maintain a young status in the trophocytes and oenocytes of old queen bees (Hsu and $\mathrm{Hu} 2014$ ). In addition, this study demonstrates that the trophocytes and oenocytes of queen bees have longevity-promoting mechanisms. This speculation is consistent with previous studies (Hsieh and Hsu 2011b; 2013; Hsu and $\mathrm{Hu} 2014$ ).

Parallel increases in age-related molecule accumulation and oxidative stress in the trophocytes and oenocytes of old queen bees indicate that high oxidative stress results in high expression of agerelated molecules (Hsieh and Hsu 2011b; Hsieh and Hsu 2013). Higher energy metabolism increases oxidative stress (Kowaltowski et al. 2009; Hsu and Hsieh 2014), and ROS are generated as by-products of energy metabolism (Halliwell and Gutteridge 1999). Therefore, the trophocytes and oenocytes of old queen bees are inferred to have high energy metabolism. However, our recent study shows that energy-regulated molecule expression is similar between young and old queen bees. These results are consistent with the current finding that mitochondrial energy utilization is similar between young and old queen bees. Thus, the patterns of age-related molecule accumulation and oxidative stress are inconsistent with those of energy-regulated molecule expression and mitochondrial energy utilization. The most likely reason is that high ROS levels in old queen bees do not derive from high-energy metabolism but perhaps from other superoxide generators, such as reduced nicotinamide adenine dinucleotide phosphate (NADPH) oxidase. This inference is supported by our previous study showing that old queen bees have high NADPH oxidase activity in trophocytes and oenocytes (Hsieh and Hsu 2013). In addition, high ROS may derive from hydrogen peroxide, which has important roles as a signaling molecule in the regulation of biological processes (Veal et al. 2007; Giorgio et al. 2007). This inference is supported by our study of worker bees (Hsu and Hsieh 2014). The above phenomena are consistent with previous studies showing that increased oxidative stress promotes the longevity and metabolic health of organisms (Ristow and Zarse 2010; Yang and Hekimi 2010; Ristow and Schmeisser 2011).

Furthermore, if high ROS levels derive from high metabolism, the superoxide most likely derives from the conversion of NADH to $\mathrm{NAD}^{+}$ (Camello-Almaraz et al. 2006). High superoxide levels then induce UCP2 expression and activate UCP2-mediated proton leak (Krauss et al. 2003). In queen bees, $\mathrm{NAD}^{+}$concentration, UCP2 expression $(n=5, P>0.05$; Figure $6 \mathrm{a})$, and $\Delta \Psi \mathrm{m}$ were similar between young and old queen bees, showing that they have similar energy metabolism. In contrast, young worker bees had high

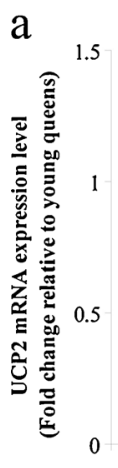

0

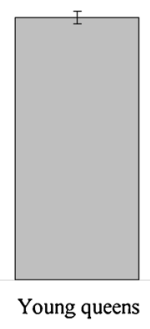

Age

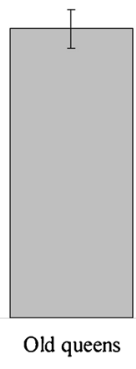

Old queens b

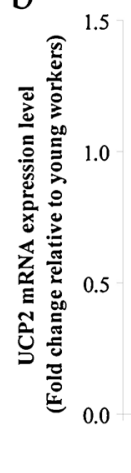

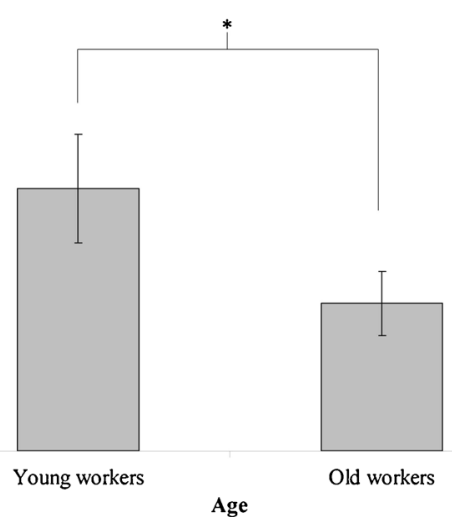

Figure 6. The mRNA expression of UCP2 in trophocytes and oenocytes was measured by quantitative PCR. a The mRNA expression of UCP2 in queen bees. The results are normalized to young queen bees, are shown as fold changes, and represent the mean \pm SEM. b The mRNA expression of UCP2 in worker bees. The results are normalized to that of young worker bees, are shown as fold changes, and represent the mean $\pm \mathrm{SEM}$. Asterisks indicate a statistically significant difference ( ${ }^{*} P<0.05$; two-sample $t$ test). 
energy metabolism and simultaneously had high $\mathrm{NAD}^{+}$concentration, high UCP2 expression $(n=$ $10, P<0.05$; Figure $6 \mathrm{~b}$ ), and high $\Delta \Psi \mathrm{m}$ (Chuang and Hsu 2013). Therefore, high ROS levels in old queen bees do not derive from high energy metabolism.

Oxidative stress decreases in the trophocytes and oenocytes of worker bees because young worker bees have high ROS levels from high mitochondrial energy utilization (Hsu and Hsieh 2014). These ROS damage lipids and proteins over time, resulting in the accumulation of lipid peroxidation and protein oxidation. Although old queen bees have high ROS levels, ROS are also present in young queen bees. ROS in young queen bees also damage lipids and proteins resulting in the accumulation of lipid peroxidation and protein oxidation. In older queen bees, lipid peroxidation and protein oxidation may be more obvious and mitochondrial energy utilization and the expression of energy-regulated molecules may show significant differences. Further research is required to clarify these questions.

\section{ACKNOWLEDGMENTS}

This research was financially supported through a CMRPD 1A0493 grant from Chang Gung Memorial Hospital, Linkou, Taiwan.

L'utilisation de l'énergie mitochondriale maintient les trophocytes et les oenocytes à l'état jeune chez les vieilles reines d'abeilles

Vieillissement / mitochondrie / utilisation de l'énergie / Apis mellifera

Die Nutzungsweise der mitochondrialen Energieproduktion hält die Trophozyten und Oenozyten alter Königinnen der Honigbiene auf einem jungen Niveau

\section{Alterung / Mitochondrien / Energienutzung / Apis mellifera}

Conflict of interest statement We have no conflicts of interest or disclosures.

\section{REFERENCES}

Allen, R.G., Tresini, M., Keogh, B.P., Doggett, D.L., Cristofalo, V.J. (1999) Differences in electron transport potential, antioxidant defenses, and oxidant generation in young and senescent fetal lung fibroblasts (WI-38). J. Cell. Physiol. 180, 114-122

Ames, B.N., Shigenaga, M.K., Hagen, T.M. (1995) Mitochondrial decay in aging. Biochim. Biophys. Acta 1271, 165-170

Artal-Sanz, M., Tavernarakis, N. (2008) Mechanisms of aging and energy metabolism in Caenorhabditis elegans. IUBMB Life 60, 315-322

Barrientos, A., Casademont, J., Cardellach, F., Estivill, X., Urbano-Marquez, A., Nunes, V. (1997) Reduced steady-state levels of mitochondrial RNA and increased mitochondrial DNA amount in human brain with aging. Mol. Brain Res. 52, 284-289

Bartosz, G., Grzelinska, E., Wagner, J. (1982) Aging of the erythrocytes. XIV. ATP content does decrease. Experientia 38, 575

Braidy, N., Guillemin, G.J., Mansour, H., Chan-Ling, T., Poljak, A., Grant, R. (2011) Age related changes in $\mathrm{NAD}^{+}$metabolism oxidative stress and sirt1 activity in wistar rats. PLoS ONE 6(4), e19194

Camello-Almaraz, C., Gomez-Pinilla, P.J., Pozo, M.J., Camello, P.J. (2006) Mitochondrial reactive oxygen species and $\mathrm{Ca}^{2+}$ signaling. Am. J. Physiol. Cell Physiol. 291, C1082-C1088

Chan, Q.W.T., Mutti, N.S., Foster, L.J., Kocher, S.D., Amdam, G.V., Florian, W. (2011) The worker honeybee fat body proteome is extensively remodeled preceding a major life-history transition. PLoS ONE 6(9), e24794

Chang, J., Cornell, J.E., van Remmen, H., Hakala, K., Ward, W.F., Richardson, A. (2007) Effect of aging and caloric restriction on the mitochondrial proteome. J. Gerontol. A Biol. Sci. Med. Sci. 62, 223-234

Chanséaume, E., Morio, B. (2009) Potential mechanisms of muscle mitochondrial dysfunction in aging and obesity and cellular consequences. Int. J. Mol. Sci. 10, 306-324

Chuang, Y.L., Hsu, C.Y. (2013) Changes in mitochondrial energy utilization in young and old worker honeybees (Apis mellifera). Age 35, 1867-1879

Donoghue, P., Staunton, L., Mullen, E., Manning, G., Ohlendieck, K. (2010) DIGE analysis of rat skeletal muscle proteins using nonionic detergent phase extraction of young adult versus aged gastrocnemius tissue. J. Proteomics 73, 1441-1453

Doran, P., O’Connell, K., Gannon, J., Kavanagh, M., Ohlendieck, K. (2008) Opposite pathobiochemical fate of pyruvate kinase and adenylate kinase in aged rat skeletal muscle as revealed by proteomic DIGE analysis. Proteomics 8, 364-377

Gadaleta, M.N., Rainaldi, G., Lezza, A.M.S., Milella, F., Fracasso, F., Cantatore, P. (1992) Mitochondrial DNA copy number and mitochondrial DNA deletion in adult and senescent rats. Mutat. Res. 275, 181-193 
Gelfi, C., Viganò, A., Ripamonti, M., Pontoglio, A., Begum, S., Pellegrino, M.A., Grassi, B., Bottinelli, R., Wait, R., Cerretelli, P. (2006) The human muscle proteome in aging. J. Proteome Res. 5, 1344-1353

Giannakou, M.E., Goss, M., Jünger, M.A., Hafen, E., Leevers, S.J., Partridge, L. (2004) Long-lived Drosophila with over-expressed $\mathrm{dFOXO}$ in adult fat body. Science 305, 361

Giorgio, M., Trinei, M., Migliaccio, E., Pelicci, P.G. (2007) Hydrogen peroxide: a metabolic by-product or a common mediator of ageing signals? Nat. Rev. Mol. Cell Biol. 8, 722-728

Guerrieri, F., Vendemiale, G., Turturro, N., Fratello, A., Furio, A., Muolo, L., Grattagliano, I., Papa, S. (1996) Alteration of mitochondrial $\mathrm{F}_{0} \mathrm{~F}_{1}$ ATP synthase during aging. Ann. N. Y. Acad. Sci. 786, 62-71

Gurd, B.J., Peters, S.J., Heigenhauser, G.J., LeBlanc, P.J., Doherty, T.J., Paterson, D.H., Kowalchuk, J.M. (2008) O2 uptake kinetics, pyruvate dehydrogenase activity, and muscle deoxygenation in young and older adults during the transition to moderate-intensity exercise. Am. J. Physiol. Regul. Integr. Comp. Physiol. 294, R577-R584

Hagen, T.M., Yowe, D.L., Bartholomew, J.C., Wehr, C.M., Do, K.L., Park, J.Y., Ames, B.N. (1997) Mitochondrial decay in hepatocytes from old rats: Membrane potential declines, heterogeneity and oxidants increase. Proc. Natl. Acad. Sci. U. S. A. 94, 3064-3069

Halliwell, B., Gutteridge, J.M.C. (1999) Free Radicals in Biology and Medicine. New York, Oxford University Press

Hsieh, Y.S., Hsu, C.Y. (2011a) Honeybee trophocytes and fat cells as target cells for cellular senescence studies. Exp. Gerontol. 46, 233-240

Hsieh, Y.S., Hsu, C.Y. (2011b) The changes of age-related molecules in the trophocytes and fat cells of queen honeybees (Apis mellifera). Apidologie 42, 728-739

Hsieh, Y.S., Hsu, C.Y. (2013) Oxidative stress and antioxidant enzyme activities in the trophocytes and fat cells of queen honeybees (Apis mellifera). Rejuvenation Res. 16, 295-303

Hsu, C.Y., Chan, Y.P. (2011) Identification and localization of proteins associated with biomineralization in the iron deposition vesicles of honeybees (Apis mellifera). PLoS ONE 6(4), e19088

Hsu, C.Y., Chan, Y.P. (2013) The use of honeybees reared in a thermostatic chamber for aging studies. Age 35, 149-158

Hsu, C.Y., Chuang, Y.L. (2014) Changes in energyregulated molecules in the trophocytes and fat cells of young and old worker honeybees (Apis mellifera). J. Gerontol. A Biol. Sci. Med. Sci. 69, 955-964

Hsu, C.Y., Chuang, Y.L., Chan, Y.P. (2014) Changes in cellular degradation activity in young and old worker honeybees (Apis mellifera ). Exp. Gerontol. 50, 128-136

Hsu, C.Y., Hsieh, Y.S. (2014) Oxidative stress decreases in the trophocytes and fat cells of worker honeybees during aging. Biogerontology 15, 129-137
Hsu, C.Y., Hu, T.H. (2014) Energy-regulated molecules maintain young status in the trophocytes and fat cells of old queen honeybees. Biogerontology 15, 389-400

Hsu, C.Y., Ko, F.Y., Li, C.W., Fann, K., Lue, J.T. (2007) Magnetoreception system in honeybees (Apis mellifera ). PLoS ONE 2 (4), e395

Hwangbo, D.S., Gersham, B., Tu, M.P., Palmer, M., Tatar, M. (2004) Drosophila dFOXO controls lifespan and regulates insulin signalling in brain and fat body. Nature 429, 562-566

Imai, S. (2009) The NAD world: a new systemic regulatory network for metabolism and aging-Sirt1, systemic NAD biosynthesis, and their importance. Cell Biochem. Biophys. 53, 65-74

Jayachandran, M., Karnicki, K., Miller, R.S., Owen, W.G., Korach, K.S., Miller, V.M. (2005) Platelet characteristics change with aging: role of estrogen receptor beta. J. Gerontol. A Biol. Sci. Med. Sci. 60, 815-819

Joo, H.J., Ma, J.Y., Choo, Y.G., Choi, B.K., Jung, K.Y. (1999) Age-related alteration of intracellular ATP maintenance in the cell suspensions of mice cerebral cortex. Mech. Aging Dev. 110, 1-12

Kawano, S., Tanimura, H., Sato, N., Nagano, K., Tsuji, S., Takei, Y., Tsujii, M., Hayashi, N., Masuda, E., Kashiwagi, T., Fusamoto, H., Kamada, T. (1991) Age-related change in human gastric mucosal energy metabolism. Scand. J. Gastroenterol. 26, 701-706

Kokoszka, J.E., Coskup, P., Esposito, L.A., Wallace, D.C. (2001) Increased mitochondrial oxidative stress in the Sod2 (+/-) mouse results in the age-related decline of mitochondrial function culminating in increased apoptosis. Proc. Natl. Acad. Sci. U. S. A. 98, 2278-2283

Kowaltowski, A.J., de Souza-Pinto, N.C., Castilho, R.F., Vercesi, A.E. (2009) Mitochondria and reactive oxygen species. Free Radic. Biol. Med. 47, 333-343

Krauss, S., Zhang, C.Y., Scorrano, L., Dalgaard, L.T., StPierre, J., Grey, S.T., Lowell, B.B. (2003) Superoxidemediated activation of uncoupling protein 2 causes pancreatic $\beta$ cell dysfunction. J. Clin. Invest. 112, 1831-1842

Kuterbach, D.A., Walcott, B.R. (1986) Iron-containing cells in the honeybee (Apis mellifera). I. Adult morphology and physiology. J. Exp. Biol. 126, 375-387

Lee, H.C., Yin, P.H., Lu, C.Y., Chi, C.W., Wei, Y.H. (2000) Increase of mitochondria and mitochondrial DNA in response to oxidative stress in human cells. Biochem. J. 348, 425-432

Lee, H.C., Lu, C.Y., Fahn, H.J., Wei, Y.H. (1998) Agingand smoking-associated alteration in the relative content of mitochondrial DNA in human lung. FEBS Lett. 441, 292-296

López-Lluch, G., Irusta, P.M., Navas, P., de Cabo, R. (2008) Mitochondrial biogenesis and healthy aging. Exp. Gerontol. 43, 813-819

Martinez, A.O., Over, D., Armstrong, L.S., Manzano, L., Taylor, R., Chambers, J. (1991) Separation of two 
populations of old human fibroblasts by mitochondria (rhodamine 123) fluorescence. Growth Dev. Aging 55, 185-191

Martins, G.F., Serrão, J.E., Ramalho-Ortigão, J.M., Pimenta, P.F.P. (2011) A comparative study of fat body morphology in five mosquito species. Mem. Inst. Oswaldo. Cruz. 106, 742-747

Nicholls, D.G. (2004) Mitochondrial membrane potential and aging. Aging Cell 3, 35-40

Nicoletti, V.G., Tendi, E.A., Lalicata, C., Reale, S., Costa, A., Villa, R.F., Ragusa, N., Giuffrida Stella, A.M. (1995) Changes of mitochondrial cytochrome c oxidase and $\mathrm{F}_{0} \mathrm{~F}_{1}$ ATP synthase subunits in rat cerebral cortex during aging. Neurochem. Res. 20, 1465-1470

Omholt, S.W., Amdam, G.V. (2004) Epigenic regulation of aging in honeybee workers. Aging Knowl. Environ. 26, pe28.

Page, R.E., Peng, C.Y.S. (2001) Aging and development in social insects with emphasis on the honey bee, Apis mellifera L. Exp. Gerontol. 36, 695-711

Passos, J.F., von Zglinicki, T., Kirkwood, T.B.L. (2007) Mitochondria and ageing: winning and losing in the numbers game. BioEssays 29, 908-917

Ramsey, K.M., Mills, K.F., Satoh, A., Imai, S. (2008) Age associated loss of Sirt1-mediated enhancement of glucose-stimulated insulin secretion in $\beta$ cell-specific Sirtl-overexpressing (BESTO) mice. Aging Cell 7, 78-88

Remolina, S.C., Hughes, K.A. (2008) Evolution and mechanisms of long life and high fertility in queen honey bees. Age 30, 177-185

Ristow, M., Zarse, K. (2010) How increased oxidative stress promotes longevity and metabolic health: The concept of mitochondrial hormesis (mitohormesis). Exp. Gerontol. 45, 410-418

Ristow, M., Schmeisser, S. (2011) Extending life span by increasing oxidative stress. Free Radic. Biol. Med. 51, $327-336$
Rottenberg, H., Wu, S. (1997) Mitochondrial dysfunction in lymphocytes from old mice: Enhanced activation of the permeability transition. Biochem. Biophys. Res. Commun. 240, 68-74

Rueppell, O., Bachelier, C., Fondrk, M.K., Page Jr., R.E. (2007) Regulation of life history determines lifespan of worker honey bees (Apis mellifera L .). Exp. Gerontol 42, 1020-1032

Savitha, S., Panneerselvam, C. (2006) Mitochondrial membrane damage during aging process in rat heart: Potential efficacy of L-carnitine and DL $\alpha$ lipoic acid. Mech. Ageing Dev. 127, 349-355

Subasinghe, W., Spence, D.M. (2008) Simultaneous determination of cell aging and ATP release from erythrocytes and its implications in type 2 diabetes. Anal. Chim. Acta 618, 227-233

Trifunovic, A., Larsson, N.-G. (2008) Mitochondrial dysfunction as a cause of ageing. J. Intern. Med. 263, $167-178$

Veal, E.A., Day, A.M., Morgan, B.A. (2007) Hydrogen peroxide sensing and signaling. Mol. Cell 26, $1-14$

Ward, M.W., Rego, A.C., Frenguelli, B.G., Nicholls, D.G. (2000) Mitochondrial membrane potential and glutamate excitotoxicity in cultured cerebellar granule cells. J. Neurosci. 20, 7208-7219

Wikowski, J.M., Micklem, H.S. (1985) Decreased membrane potential of T lymphocytes in ageing mice: Flow cytometric studies with a carbocyanine dye. Immunology 56, 307-313

$\mathrm{Xu}$, D., Finkel, T. (2002) A role for mitochondria as potential regulators of cellular life span. Biochem. Biophys. Res. Commun. 294, 245248

Yang, W., Hekimi, S. (2010) A mitochondrial superoxide signal triggers increased longevity in Caenorhabditis elegans. PLoS Biol. 8, e1000556 